\title{
Path Choice of Creating Cultural Industry Highland in Changbai Mountain Tourism International Leisure Mountain
}

\author{
Yang Hui ${ }^{1,2}$ \\ ${ }^{1}$ Changchun University of Finance and Economics, National High-tech industrial development \\ district of Jingyue, Changchun City, Jilin, China \\ ${ }^{2}$ Tourism College of Changchun University, Changchun, Jilin, China
}

Keywords: Changbai Mountain; Tourism Resources; Special tourism Brand

\begin{abstract}
Changbai Mountain area has a wealth of tourism resources, is conducive to the development of tourism. After years of development, Changbai Mountain entered the transition period of tourism development, as soon as possible to build a unique international tourist attractions in Changbai Mountain is one of the important tasks of tourism, which requires Changbai Mountain from the characteristics of tourism resources to analyze the status of Changbai Mountain tourism products development and The improper development of resources, the irrational product structure, the lack of connotation construction and other issues, in order to promote the development of Changbai Mountain tourism products related countermeasures. This paper demonstrates the necessity of expanding the scenic spot of Changbai Mountain and the favorable conditions for Changbai Mountain to make famous tourist attractions at home and abroad, and put forward the development measures such as developing long-term tourism, multi-form tourism, ice and snow tourism, exploring the intrinsic potential and viewing depth of scenic spots.
\end{abstract}

\section{Introduction of Changbai Mountain Tourism Resources}

Changbai Mountain ecological system integrity, preserved large tracts of virgin forest, wild resources is extremely rich, more than 1500 kinds of animals, plants 2277 kinds, with rich resources, medicinal resources. Wild vegetables, wild fruits, fish, frogs and other nutrient-rich, delicious, green pollution-free; ginseng, Gastrodia, Rhodiola and other medicinal resources rich, rare varieties more.

Magical original geological landscape resources, Changbai Mountain for the body sleep volcano, the history of several eruption, formed under the underground river, underground hot springs, underground cave, there are alpine Tianchi Lake, vertical landscape with magic spectacular, original natural landscape. Changbai Mountain set lakes, rocks, waterfalls, canyons, hot springs, forests and other resources in one, from the foothills to the top of the mountain to the temperate zone to the typical plant type. Unique strange snow and ice tourism resources, the climate has given Changbai Mountain unique snow and ice tourism resources. Changbai Mountain average altitude of $1640 \mathrm{~m}-1825 \mathrm{~m}$, the temperature is often minus 15 degrees, winter time is long. Unique climatic conditions caused Changbai Mountain area snow date is long, about 250 days, snow thickness of 1-2m, snow long, thick snow, good snow ${ }^{[1]}$.

In addition, Changbai Mountain area spa is widely distributed, abundant water, often appear fog and ice hanging. Changbai Mountain at the foot of the Han, but also living in Manchu, Korean, Mongolian and other ethnic minorities. Different ethnic groups in the language, clothing, living, festivals, weddings and funerals, and other characteristics, such as the Korean people Chong Li, clothing, food and folk customs, is an important folk tourism resources in Changbai Mountain area. Changbai Mountain is the first batch of 5A-level scenic spots, but its number of tourists and total tourism income and the famous 5A-level scenic spots are still a large gap between the main problems concentrated in the remote location, shorter travel time, tourism resources development level Shallow, service facilities are not perfect, limited range of scenic spots, high-level tourism products less tourism projects are more single and tourism resources, cultural excavation is not enough. 


\section{Current Situation of Changbai Mountain Tourism Development}

Changbai Mountain is rich in tourism resources and diverse. After years of development, Changbai Mountain tourism resources have been constantly excavated, in addition to traditional tourism products, some of the participation, leisure tourism products have been developed and promoted, such as snow projects. Changbai Mountain tourism products are changing from a single to diversified, from sightseeing to sightseeing, leisure, sports, health combined with the direction of change. But in the development process, the connotation is not prominent, the characteristics are not obvious and so on ${ }^{[2]}$.

In recent years, the development of tourism resources in Changbai Mountain has mainly focused on the development of natural tourism resources. The products are mainly tourism and tourism, and the development of tourism products is mainly. On the existing tourism products, the seasonal distribution is obvious, tourism products are mainly concentrated in the summer, mainly to sightseeing, skiing in winter, mainly in the spring and autumn tourism product development less. Product structure of the unreasonable, to a certain extent, led to Changbai Mountain tourism season is obvious, visitors stay short time, low level of consumption and other issues. In the process of long historical development, Changbai Mountain not only formed rich natural resources, but also accumulated unique human resources. However, from the development of the status quo, Changbai Mountain area of natural tourism resources continue to develop, lack of humanistic tourism resources development. The region's long history and culture, diverse folk customs, unique anti-Union culture, rich festivals, and so on, the development of the use of less, mostly shallow level development, the lack of high-grade tourism products.

The development of natural tourism resources, in the early more extensive development, management, Changbai Mountain tourism resources have been over-developed phenomenon. The discharge of domestic sewage will be caused by the water environment of the Songhua River, the west slope of the mountain tundra with a number of roads. At the same time, with the influx of tourists, the trampling behavior on the surrounding vegetation and soil have a great impact on the living environment of animals and animals threatened, such as the birch forest dead, alpine garden has been destroyed, some plants Occurrence of secondary succession, and some even extinction. Changbai Mountain unique natural tourism resources are advantages of the development of natural tourism, product development is also more effective ${ }^{[3]}$.

\section{Changbai Mountain Tourism Culture Development Strategies}

Changbai Mountain scenic tourism resources, in addition to the core area has the world's highest and deepest crater lake and waterfalls, hot springs, lava and the original ecological forest, snow and other landscape resources, but also added more attractive and well-known tourism resources. Fig. 1 shows Changbai Mountain Tourism culture development strategies.

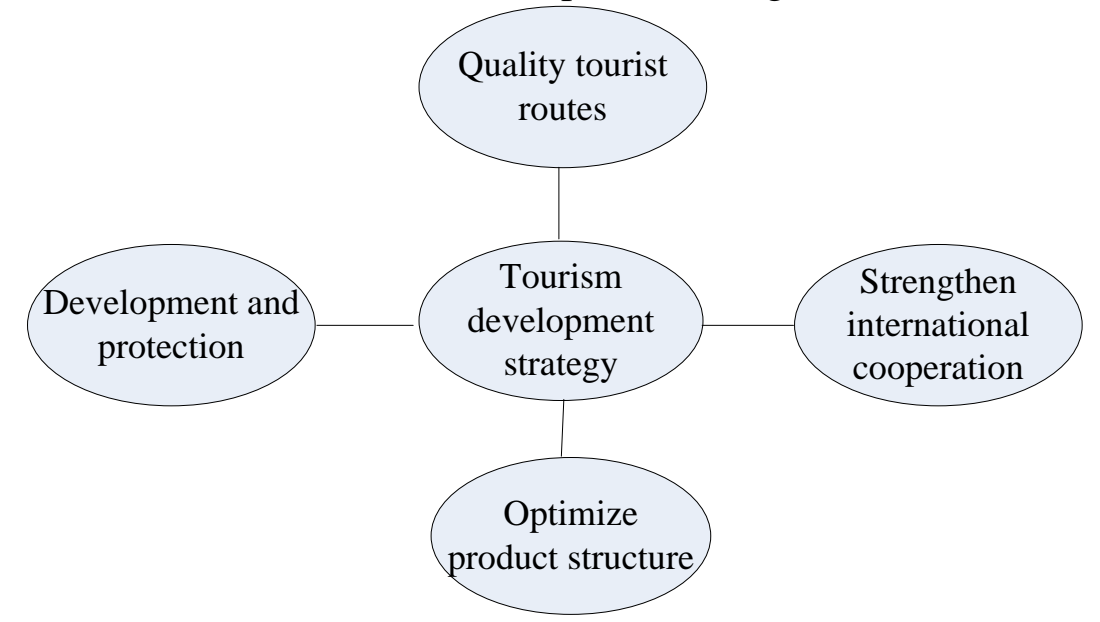

Fig. 1. Changbai Mountain Tourism culture development strategies

Changbai Mountain area of the traditional public tourism to Changbai Mountain has brought 
many ecological and environmental problems, the construction of tourist facilities and visitors to enter the wild animals and plants living environment by Wei rib. The development of long mountain tourism, the most important thing is the development of eco-tourism, ecological and natural environmental protection and social and economic development of the organic combination. In view of Changbai Mountain tourism product structure status, Changbai Mountain should be based on resources, market-oriented, sustained and healthy to carry out natural sightseeing tourism, continue to develop and promote cultural tourism, leisure travel, sports and other products to achieve new and old products complement, desalination season tour. And ultimately build Changbai Mountain tourism convergence, sightseeing and experience, natural and cultural blend of product system $^{[4]}$.

Changbai Mountain tourist attractions is an international tourist attractions across the three countries.Therefore, the development of its tourism industry, development and prosperity, inseparable from the provinces and countries in the region's joint efforts. As the core area of tourism in Jilin Province, and actively lead the relevant provinces and countries signed a joint development and operation of Changbai Mountain tourism cooperation agreement in the agreement to clear the responsibilities and interests of all parties, manage the domestic tourist attractions, to expand the local tourists, as Transit tourists to provide convenient visa clearance conditions, the common big Changshan Mountain tourism business bigger and stronger. In the design of the tourist route, should be substantial, perfect, to enhance the original core area two to three days on the basis of short-distance tourism, focus on creating some throughout the region, long-distance travel routes. At the same time in the most attractive core area Vigorously develop to attract tourists long live, long stay of leisure, convalescence, health and tourism, so that the formation of a unique domestic tourism brand.

\section{Establish Changbai Mountain Tourism Brand}

Relying on the rich tourism resources, Changbai Mountain area carries out a variety of tourism activities. Make full use of Changbai Mountain unique tourism resources, the development of special tourism products, improve the competitiveness of Changbai Mountain tourism products, Changbai Mountain tourism development must solve the problem. Changbai Mountain characteristics of tourism products should rely on the development of tourism resources, mining connotation, so that the product has a unique, iconic construction of tourism brands ${ }^{[5]}$. Fig.2 shows Changbai Mountain ice and snow tourism.

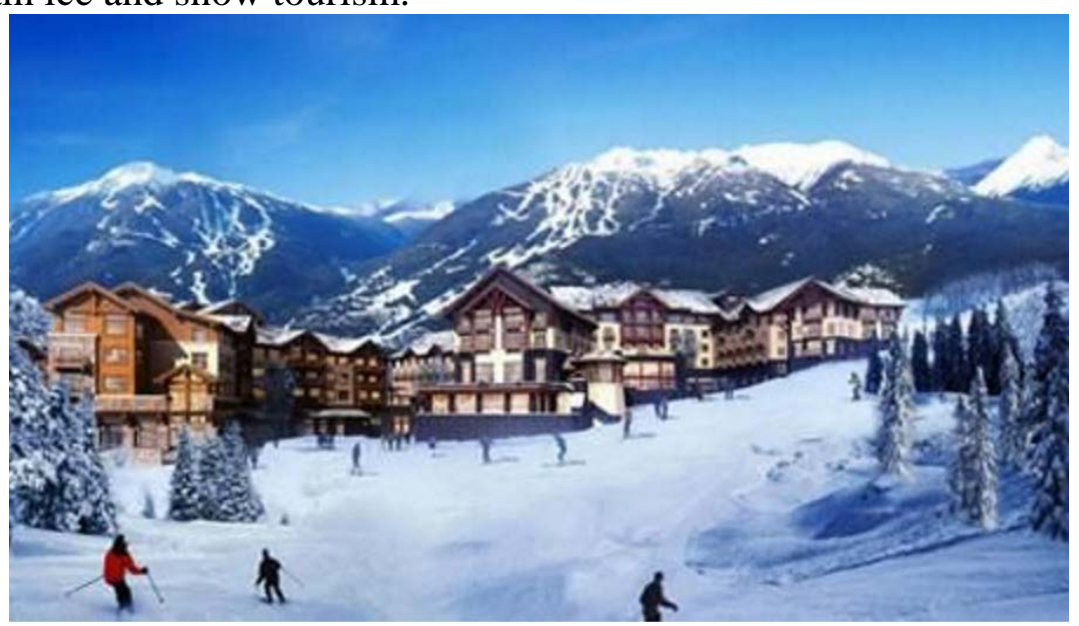

Fig.2.Changbai Mountain ice and snow tourism

Changbai Mountain preserved in the northern half of the Eurasian continent is a very complete forest ecosystem, the summit around 2500 meters above sea level, steep and steep, majestic different. Nature for Changbai Mountain left a geological landscape, waterfalls, rivers, forests and other resources, high resource level. Changbai Mountain summer cool and cool, autumn fog cool, the average temperature in July is not more than 10, the number of hot springs in the region, widely distributed, with hunting grounds, ski resorts, resort facilities and other facilities, suitable for 
summer, health tourism activities. Changbai Mountain should continue to strengthen the development of such resources, create Changbai Mountain body leisure health characteristics of tourism products.

Changbai Mountain area has a wealth of cultural tourism resources, should rely on such resources, to carry out cultural experience characteristics of tourism products. Carry forward the local folk customs, the development of traditional ethnic tourism projects, to create national folk customs experience tour brand. Changbai Mountain tourism are still mainly for the natural sightseeing tour shallow level, and historical and cultural, anti-union culture, national culture and other cultural association. This will keep the tour at sightseeing, while the lack of cultural precipitation. Excavation of historical and cultural connotations to explore the Goguryeo culture, Manchu culture, shaman culture, we can create historical and cultural tour brand. Relying on the existing festivals, rich festival, deepen the festive connotation, to create festivals experience tour brand. In addition, Changbai Mountain should use natural scenery, ice and snow resources, biological resources for market demand, carry out photography, sports, inspection and other special characteristics of tourism products.

\section{Conclusions}

Cultural needs are the fundamental motivations of tourism, cultural resources are the core resources of tourism, and cultural exchange is an important function of tourism. Promote Changbai Mountain leisure tourism economic development need to enhance the cultural quality of tourism. Will be Changbai Mountain to create an international leisure and tourism mountains, be sure to explore its deep scientific and cultural resources In summary, by virtue of the long Daxia Mountain Scenic Area superior geographical advantages, rich and unique tourism resources, has laid a good foundation for the development of tourism, Changbai Mountain tourist destination will be able to meet the needs of tourists in the scientific and cultural level, in the field of tourism services to meet the tourists, to be able to meet the needs of tourists in the field of tourism services, consolidate the loyalty of tourists to leisure travel, as tourists take the initiative to carry out the image of the driving force.

\section{References}

[1] Shi Peiji, Li Xianfeng. Tourism image communication research [J]. Journal of Southwest University for Nationalities: Humanities and Social Sciences, 2006 (8).

[2] Chen Chengli. Promote the rapid development of cultural tourism in Changbai Mountain [J]. Contemporary Economy, 2012, (6): 96-97.

[3] Lu Hongtao. Study on the Influence of Tourism Destination Image on Visitors' Word Reputation [D]. Liaoning University, 2012.

[4] An Guo zhu. Changbai Mountain eco-tourism development and marketing promotion [J]. Changchun: Jilin University, 2013.

[5] XU Lin shu. WANG Zhao ming. Study on Science Intervention in Long Mountain Leisure Tourism [J]. Green Technology, 2014 (6). 
基金项目:

1.Social Scientific Research Programme “The 13th Five-year Plan” of the Education Department of Jilin Province, China (2016-560)

2.The Major Programme of Social Scientific Research “The 12th Five-year Plan” of the Education Department of Jilin Province, China（2015-596）

3.The Scientific Research Programme of the Tourism College of Chang Chun University. (Innovation and development fund of the Tourism College of Chang Chun University (2016-20))

4.The Teaching Reform Programme of the Tourism College of Chang Chun University. (Innovation and development fund of the Tourism College of Chang Chun University (2016-09)) 